\title{
Notes on the vocalizations of Wedge-tailed Grass-finch
} (Emberizoides herbicola)

\section{Peter Boesman}

In the following we briefly analyze and compare voice of the different races of Wedge-tailed Grass-finch (Emberizoides herbicola). We also try to quantify the extent of any vocal differences using the criteria proposed by Tobias et al. (2010), as a support for taxonomic review. We have made use of sound recordings available on-line from Xeno Canto (XC) and Macaulay Library (ML).

An overview of song per region, illustrated with sonograms:

Panama $(n=1)$

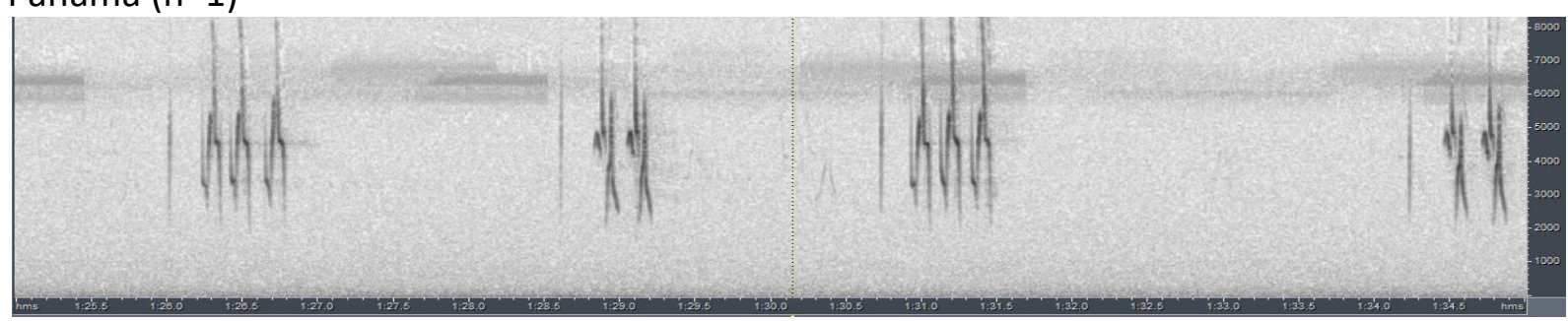

Northern S America

$S$ Ecuador

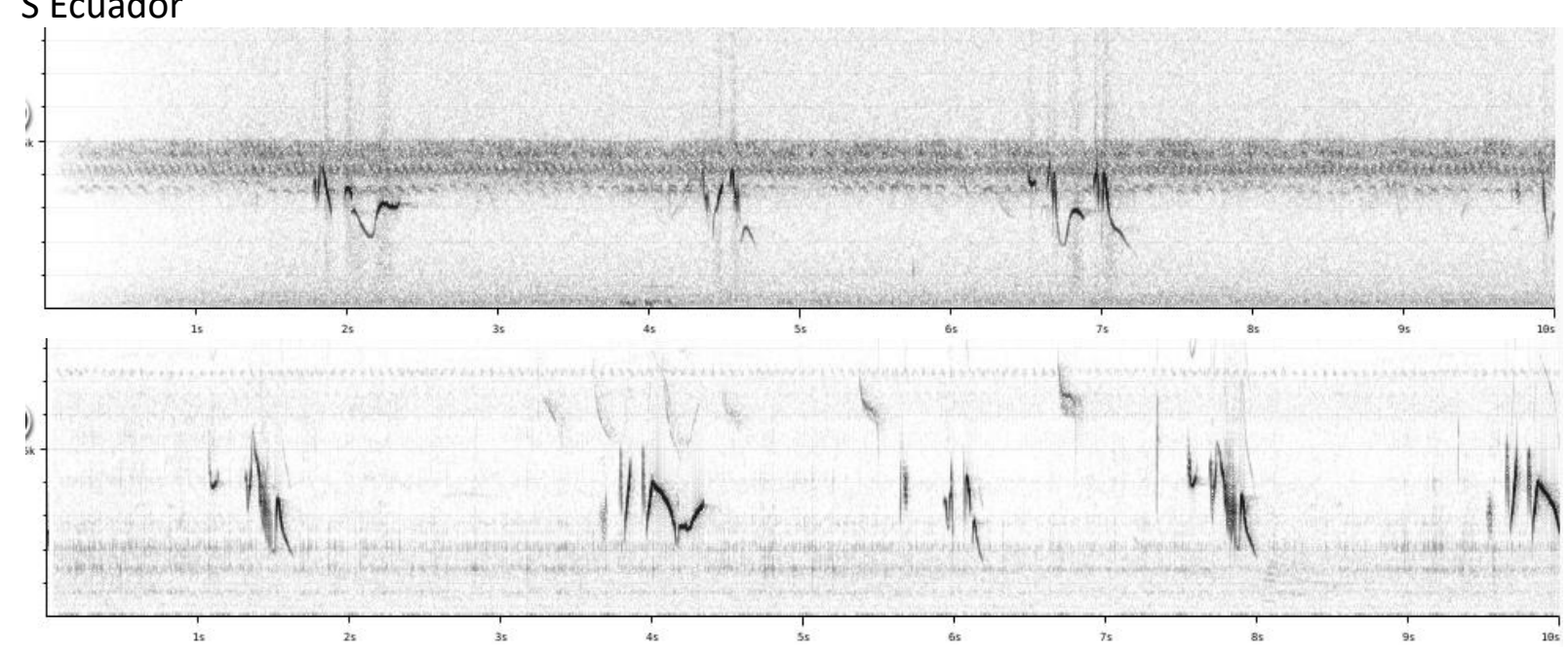

N Peru

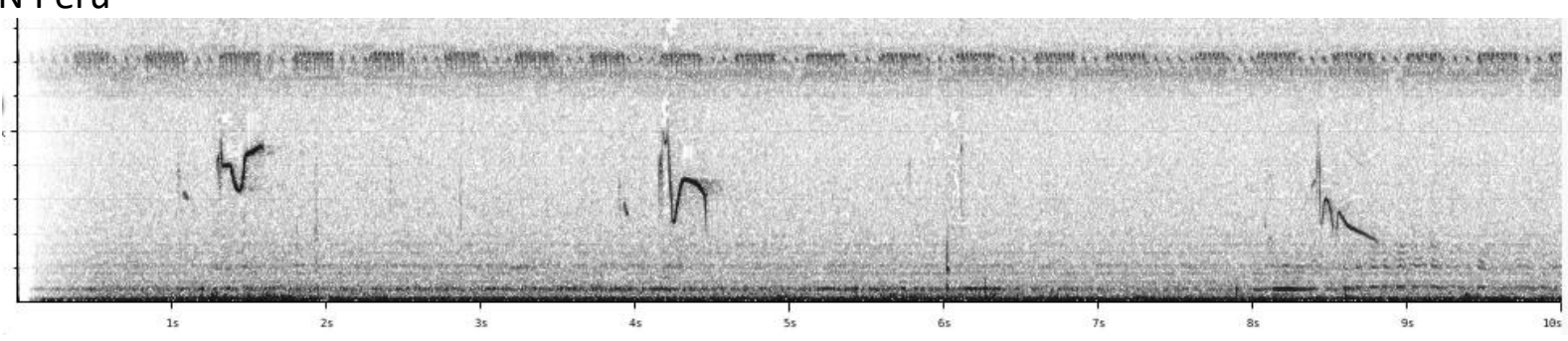


HANDBOOK OF THE

BIRDSPFIUE WORLD ORNITHOLOGICAL NOTES

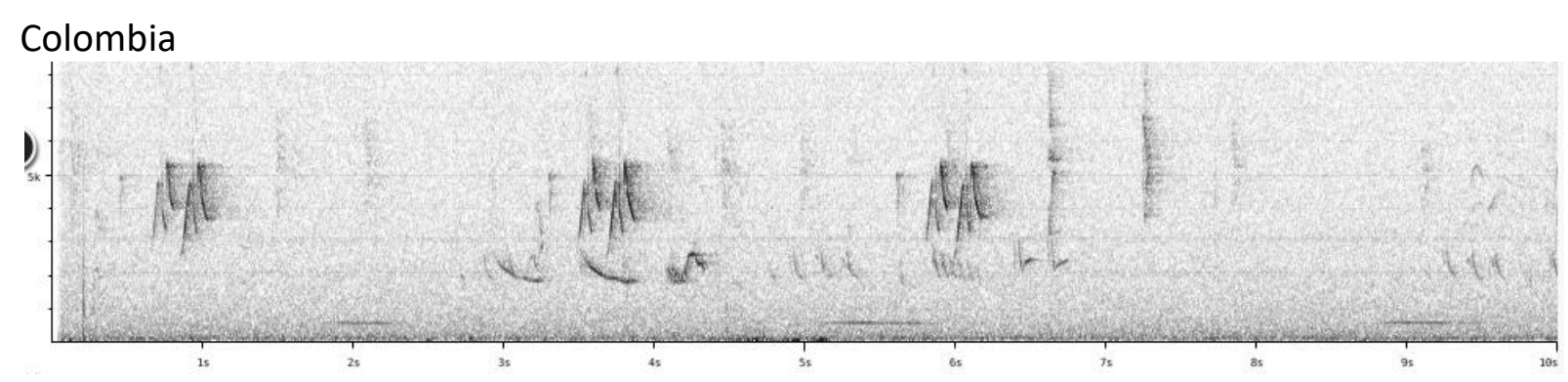

SE Venezuela

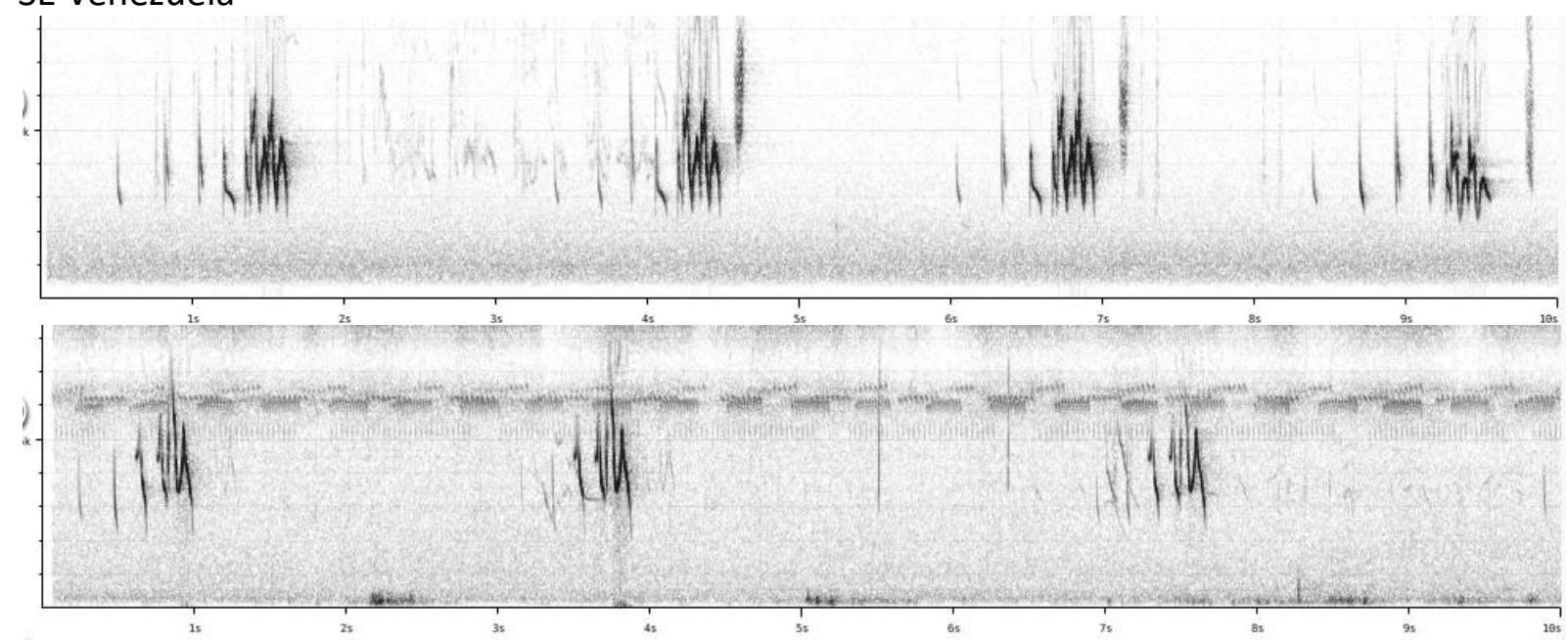

French Guyana

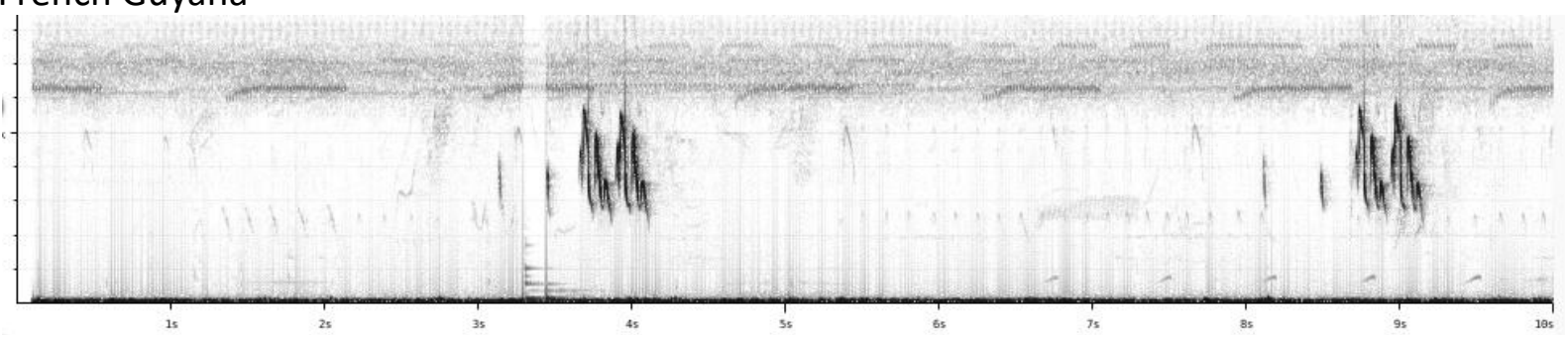

Southern S America

Bolivia

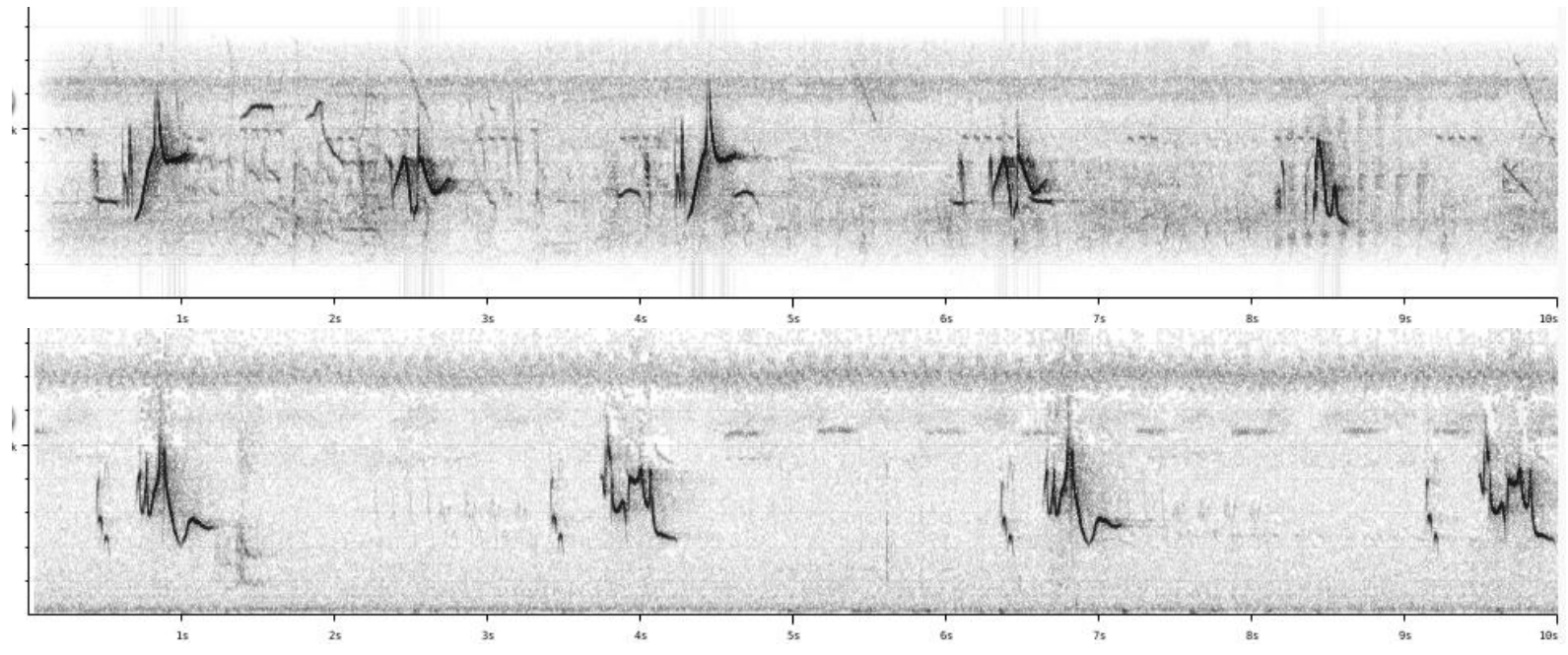




\section{HANDBOOK OF THE Allue}

\section{ORNITHOLOGICAL NOTES}

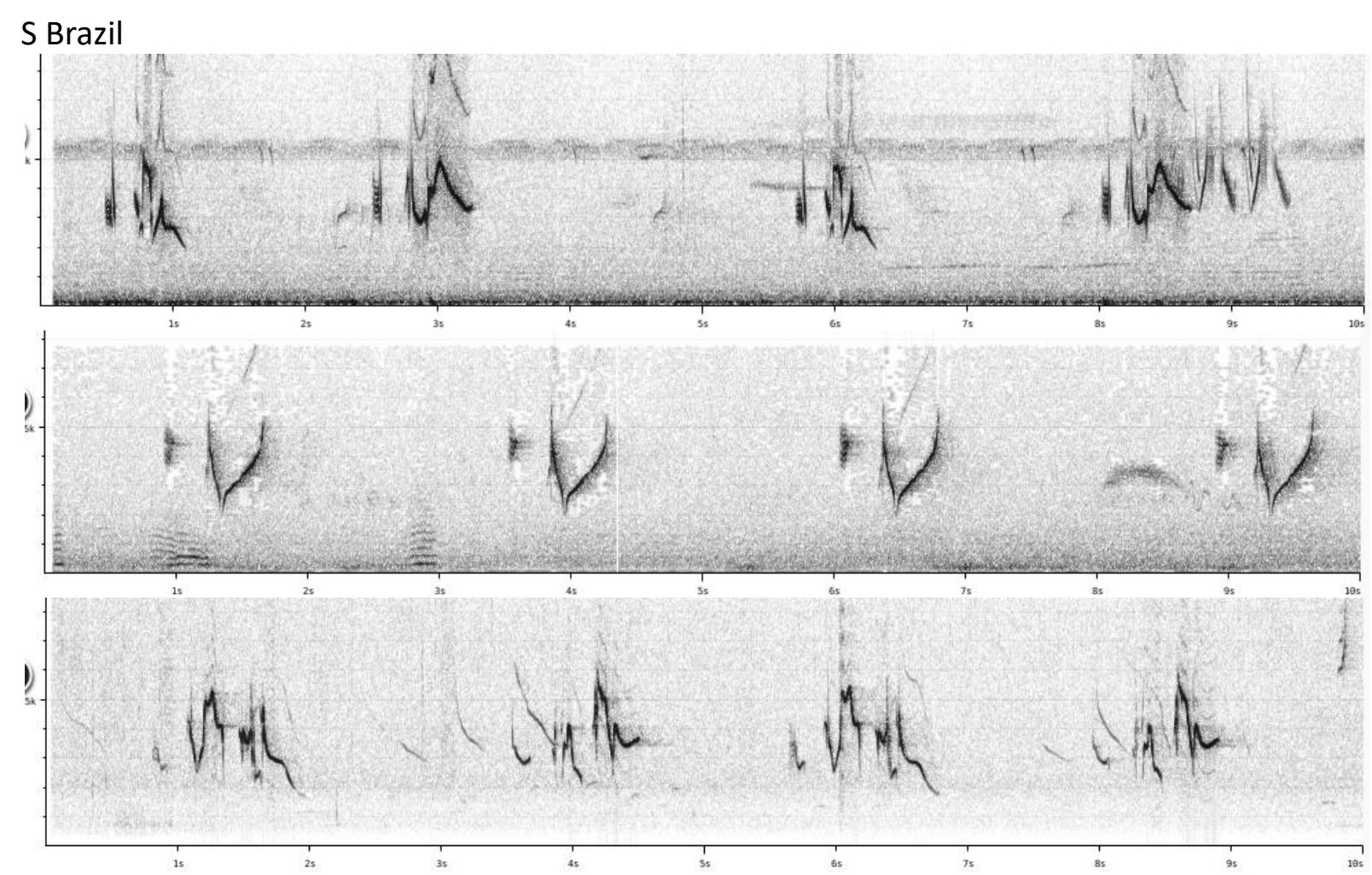

Northern S America group (excl. S Ecuador/N Peru and NE Brazil) typically has a song starting with one or a few "pit" notes followed by 2-3 short complex notes, of which usually 2 are about identical. "pt..pit..tchip..chee.cheew"

Southern S America group (and S Ecuador/N Peru) typically has a song which is quite variable, but always contains 1 or 2 complex notes with clearly slurred parts and without any repeats.

Vocally it would thus seem that the population in S Ecuador and N Peru (which is supposed to be part of sphenurus) rather fits herbicola!

In the same way, birds from Belem area (S of the Amazon) fit herbicola, not sphenurus!:

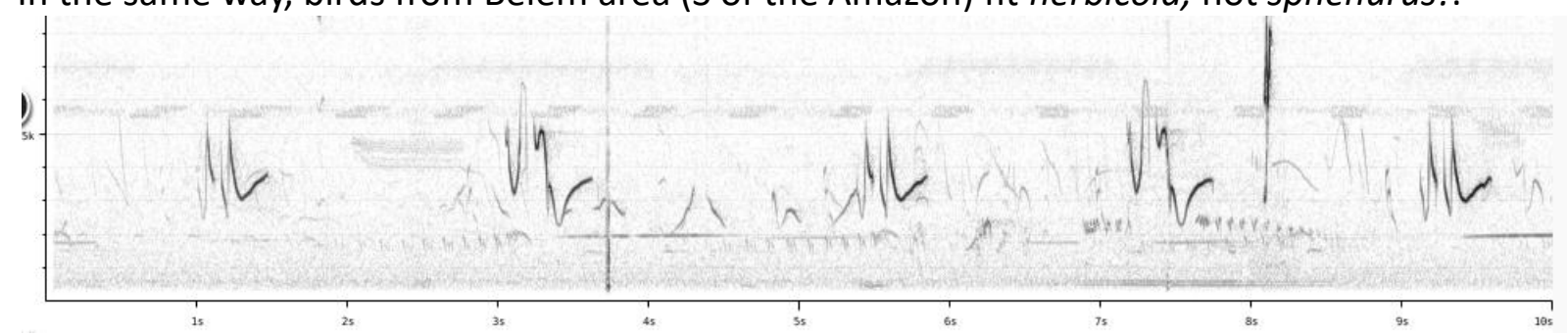

There is thus vocally a clear dividing line by the river Amazon.

Vocal differences can be quantified as follows:

Southern group lacks any repeats (score 2 ) and has the longest slurred notes (score 2).

Total score about 4. 
We have only a single recording of Central America, consisting of an introductory "pit" note followed by a short complex note repeated 2-3 times (sometimes $2+3$ in one phrase). Based on a single recording of Central American races, little can be said about vocal difference $v s$ Northern S America group, but it would seem that identical repetitions of a single note are even more pronounced here (Panama).

This note was finalized on 2nd July 2016, using sound recordings available on-line at that moment. We would like to thank in particular the many sound recordists who placed their recordings for this species on XC and ML.

\section{References}

Tobias, J.A., Seddon, N., Spottiswoode, C.N., Pilgrim, J.D., Fishpool, L.D.C. \& Collar, N.J. (2010). Quantitative criteria for species delimitation. Ibis 152(4): 724-746.

\section{Recommended citation}

Boesman, P. (2016). Notes on the vocalizations of Wedge-tailed Grass-finch (Emberizoides herbicola). HBW Alive Ornithological Note 397. In: Handbook of the Birds of the World Alive. Lynx Edicions, Barcelona. (retrieved from http://www.hbw.com/node/1253791 on 1 December 2016). 